\title{
Research in Greek Universities: Non-compatible Categorizations and Dysfunctional Structures
}

\author{
Argyris Kyridis \\ Department of Preschool Education, Aristotle University of Thessaloniki \\ University Campus - Faculty of Education, 54124, Thessaloniki, Greece \\ E-mail: akiridis@nured.auth.gr \\ Nikos Papadakis \\ Department of Political Science, University of Crete \\ University Campus, Rethymnon, 74100, Greece \\ E-mail: nep@pol.soc.uoc.gr \\ Evagelia Kalerante \\ Department of Preschool Education, University of Western Macedonia \\ 3rd Km Florinas-Nikis, 53100, Florina, Greece \\ E-mail: ekalerante@uowm.gr
}

Christos Zagkos (Corresponding author)

Centre for Educational Policy Development (KANEP/GSEE)

3rd Septemvriou str, 10432, Athens, Greece

E-mail: zagba12003@yahoo.gr

Received: June 5, 2012

Accepted: October 15, 2012

Online Published: October 25, 2012

doi:10.5430/ijhe.v1n2p198

URL: http://dx.doi.org/10.5430/ijhe.v1n2p198

\begin{abstract}
The issue of research within the Greek Universities pushes forward the learning and maturation procedure through action, a procedure that will change the framework of the University Community function by developing, on the basis of a rational reorganization, structural relationships with society. This study presents and analyzes the state of scientific research in the Greek university in the present unfavourable economic and social era. In this paper are analyzed inter alia, the structural malfunctions of the Greek university structures, the interaction between academic research and politics, the ethics and the good practices related to the scientific research in Greece.
\end{abstract}

Keywords: Research, Greek higher education, Scientific ethics

\section{Research in Greek University Institutions within the environment of knowledge society}

Within a period of economic system recession and the capitalist model development the question of "educational issues management" (Jessop, 2002; Hobsbawm, 2011) and the University contribution to the financial recovery (Feller, 1990) is being recurred. Irrespective of the theoretical models placing the economic recession in different frameworks, either incorporating it in the shock doctrine or interpreting it as a reorganization transitional status, the issue deriving is that the knowledge society, as a semantic invention, is tied to the knowledge management as resources (Berger \& Luckmann, 2011). The University in terms of an economic, educational and national unit is called upon to develop strategies by utilizing the formal and informal organization historic experiences tied to the institutional model of composition and function determination as well as the informal organization patterns defined and developed by the subject carriers. 
The issue of research within the Greek Universities pushes forward the learning and maturation procedure through action, a procedure that will change the framework of the University Community function by developing, on the basis of a rational reorganization, structural relationships with society. It is about a crucial moment which inaugurates a complicated and difficult to prospect transitional period (Bologna Process, 2005; Clark, 1983).

The introversion within the Greek University was functioning as a safety valve to reduce the tensions among the University community members within an isolation procedure ensuring, on the other hand, affiliations, relationships and scientific objects balance by decreasing controversies and attritions. One could tell that the University inactivity was functioning as a relieving condition in a model in which the silent knowledge was projected.

The reference to research as a productive procedure contains rigidities' cancellation and the principles legalization, such as the internal and external monitoring over an extroversion procedure with a threefold evaluation form by: a) the outside-University community, b) the University community. The outside-University community is a data source in which issues to be investigated lie and economic, social, historic scientists' perceptiveness in pushing forward the issues to be studied is tested (Gibbons, 1998; Gibbons, 2006).

Within the society with its broader open internet interconnections (Hindmoor, 2004), the research discourse, in any form as a research deduction, becomes an open issue to be investigated and here lies the society dynamic function beyond the classical democratic organization and expression patterns in which the product generated as knowledge through the University research is available to be studied and evaluated by the social subjects as well as broader political, economic and social institutions. At this point, the concept of transparence is underscored and the research is tied to the University visibility. A post-modern super-visual monitoring was functioning in which University structures and carriers are tested and controlled by subverting the formal or informal "inaccessible status" in the University system. A mobility of inter-contacts is concurrently generated in which a research procedure readjusts functional relationships through a legitimate spectrum of consultation attuned to the research commands as stages of study settlement and preoccupation expression.

The research functions as a redefinition procedure of the scientist and scientific objects' conceptualization. In the issue of the scientist's definition opportunity structures seem to be created (Koubi, 2000) since the criteria are diversified and intelligence, skill and knowledge are evaluated as incorporation prerequisites in the research groups (Florida, 1999; Hill, Hoffman \& Rex, 2005). It is perhaps an opening towards the lower social classes that seem to be sub-represented at least in the Greek Universities. The research sparks off the traditional scientific domains to be modified by pushing forward new knowledge structures, new communications and cognitive patterns by subverting the University subjects' authority itself that seems to be based on the standardized confined knowledge.

Research, as a procedure, is related to the social mission, as it has been analyzed, in which the University as a research center is available to society that symbolically seems to dictate the cognitive domains necessary to its survival and evolution, including the economic, social and cultural terms set as constituents of its structure. As it has already been mentioned, the opportunity structures for the social subjects to estimate the research results are expanded since all research stages are reported in an attempt to cancel the University isolation or the inaccessible or impenetrable status of knowledge. Therefore, knowledge itself is redefined under broader utility and truth criteria. Definitions are pursued from the beginning about the utility and truth themselves beyond the doctrinal and transcendental conceptualizations that in social terms generated exclusion through ambiguous categorizations in experts and non-experts that comprehend or interpret knowledge.

\section{Objectivity in research practice}

Which are the ruling mechanisms that compose and monitor the scientific production? The assignors and its consumers are the ones in the first place. It is easy for someone to claim that the assignor is no other than the society itself since science is a social possession. No one raises objections but society is not an indivisible entirety that is totally consistent with its choices. Society itself has ruling structures, decision making poles and is governed by a grid of ideological realities parameterization. The social domain called science inherits all the social entirety attributes and functions as its sub-total.

The science financier sets the terms of its production (Smith, 2011; Vest, 2007) - not only the ideological direction but also the type of the results in many cases. Who finance science? Its institutional consumers do so primarily; for example, big industries, companies or state and hyper-state organizations as well as the same participants through the state choices. Who establish the prevailing ideological framework? The same as above do so. Indeed, they establish the existing prevailing ideological framework, the one that governs society, too - globalized or not - as an entirety. 
Even the state itself, the worded society administrating expression establishes ideological terms no other than the prevailing ideology, the one generated and established by the civic ideological state mechanisms (Althousser, 1990).

Prevalence in science is not expressed only by the institutions involved and the ideologies that profess, but, moreover by the entities that have managed to be prevalent in these procedures. They are scientists themselves, too. They are the ones who have been acknowledged by their work as prevailing figures in the scientific community. They are laboratory directors, editors and international scientific journals judges, the ones that have possessed higher staff positions based more on their political interconnections and less on their scientific work (Martin, 1981). All these are the players that formulate the scientific production framework as well as its microcosm. They also contribute to the scientific production, comprising the forces co-ordination that stabilize or disturb the social area of science. They are the same forces that are responsible for the maintenance of the scientific status.

For professional researchers who work and are salaried by universities and research centers - the generation of cognitive products (Radford, 1997) means the acknowledgement and salary readjustments through the upward grades evolution. It is observed that before the altar of acquiring the greatest possible benefits (Colbeck, 2002; Creamer, 1999; Colbeck, 1998) from knowledge production and within the frameworks of a terrifying competition among producers, the science workers - that is the researchers - devote themselves to their own competition aiming at the acquisition of a social prestige reward. And this is the summit of scientific competition. According to D. Osmond "universities and research centers have flooded with blood" (Osmond, 1983). Their moral values as well as all those values that render their production valid and reliable on the basis of the data acquisition and process manner, on the power of individual discourse, their presence in the communication procedure and so forth are sacrificed before the same altar. At the same time, their work itself is disdained and sold out because it is deprived from one or more of its attributes that render it valuable and favor it with the value- priority within the economic and social production.

Based on the above observations, the issue of research validity and reliability seems to be the demand and the Greek university community ought to redefine its role. Provided that all these procedures required by the university community to ensure the correct scientific act and, consequently, the truth of the scientific achievement are upheld, the scientific production will be valuable. The result may be cancelled in case these procedures are distorted or not upheld. Individual production is on the quest for its collective confirmation so that it acquires social acceptance and value. Society has put into force those mechanisms aiming at the confirmation of individual production - in this sense scientific production is perhaps the only type of production with a name - in order to become a social possession. All these austere production procedures are summoned up, as it seems, by the importance of knowledge as a social possession.

\section{Research and political area: interconnections and definitions}

Research is tied to theory and practice which sets the functional framework of science itself (Chalmers, 1982) as a mission to discover the truth through transparent and monitored procedures (Nachman, 1986). Science is the quest of valid knowledge (Merton, 1968). All the above mentioned, of course, are in force under the terms stated by T. Kuhn (1962) in relation to the subjective perception of truth and reality on the scientist's part and P. Feyerabend's (1975) standpoint according to which science is not the only way of perceiving reality but an alternative way of comprehending it.

Knowledge production and management is not exclusively the individual participants' responsibility and activity but is integrated in the modern state managing responsibility which, by undertaking to finance education, actually undertakes the knowledge production, reproduction and dissemination within a social environment. Knowledge is, above all, a social construction (Brannigan, 1982; Mulkay, 1976; Rayets, 1971). The production procedure and its dissemination procedure seem to have all the attributes stemming from the social and political content.

The issue of objectivity in the research results assignment, conduction and dissemination presupposes a common communication framework between the research groups and the state and obviously a way of certifying its validity (Barnett, 1994; Doherty, 1994; Ellis, 1993). All these are in force under the condition that the research results will become the society's property, be utilized and contribute to the political, social and economic structures reformation. It is perceived that a research financing and the whole multiple support framework provided by the state mechanism under the contribution of its structures and carriers will return reciprocally, functioning as an investment and maximizing the benefit for the social entirety. Knowledge as a product and resource, actually stemming from the production procedure to which specific political systems and universities carriers contribute, acquires an economic and social value. 
The scientists' adjustment to the scientific knowledge production procedure urges the adjustment to a social rules grid - formal and / or informal - ensuring the production quality and certifying the production validity. The creator's individuality is reconciled with the social so that production acquires a social value. Social control mechanisms and social rules define the limits and the action result. When the social rules are not upheld it means that individuality is prevalent, the procedure is, therefore, cancelled. In this case, the actor not only cancels his production but shows disrespect towards social conscience and those that are similar to him. Knowledge production as a scientific procedure should be constructed on the basis of confidence, mutual confidence among the science producers and workers and social confidence in which the scientists revel from the social corpus. The counter -ethical scientific behavior entails confidence vacillation and production disturbance.

\section{Greek Universities in Research}

\subsection{Institutional Framework}

Universities, with two natures in their organizational capacity, as educational and research institutions, communicate and, at the same time, produce knowledge - namely scientific knowledge. Universities are the natural research areas, exactly due to their two natures organizational pattern: teaching and research are organically related between each other since: "teaching informs research and research informs teaching" (Gull, 2010). Thus, the Greek university education organizational and ideological scheme correctly ensures the theoretical and practical "co-existence" of teaching and research concurrently creating the necessary institutional prerequisites. For example, it legislatively ensures the double mission of the Higher Educational Institutions (AEI), the personnel double mission and capacity working in them (Teaching and Research Personnel), the personnel election, appointment and evolution criteria etc. The P.D. 160/G.G. 220/2008 (Model Internal Regulation). "Every Higher Educational Institution practices teaching, research and other work [...] The academic function contains the research and teaching work, the syllabuses..." (art.1). The particular law is comprised by approximately 12.200 words. The work "research" is quoted 6 times in the article (1) Application field - Administration and economic function organization and nowhere else. The total use of the verb, noun and adjective "research" is quoted 31 times $(0,25 \%)$ (6 times in the general description of the work the mission of Higher Educational Institutions and 25 times in other points such as (personnel work, libraries, scholarships, HCI, strategic scheduling - especially here it is made clear that the strategic scheduling refers only to functional issues). It is comprised by 61 articles.

As it is observed there is no article directly related to research and no reference to terms, structures and functionality. No reference is made to research laboratories organizational conditions, financing or personnel within this framework. The political system probably hesitates to undertake the role in the research organization and actually its reinforcement.

The only positive thing that could be found in the Model Internal Regulation of the Ministry of National Education and Religion related, perhaps, to research is article 4 about ethics. Without being referred to as such, it seems that it regards research. In particular, the "Ethics Committee" (art. 4) "[...] has the objective of ensuring, maintaining and applying ethics rules...", without any definition about them. This means that no reference is made to a prerequisites grid that should be maintained by individuals and organizations involved in the research procedure. How are they going to be controlled? (It is characteristic that only the university carrier of the University of Thessaloniki has published academic ethics rules)

Even though the institutional carrier that every time defines through law enactment the Greek universities pattern and functional philosophy seems to have combined under the same institutional, organizational, social and ideological framework research and teaching, it eventually refers superficially and indirectly to research. That is the Greek government is reluctant to invest on research. Although the state has not yet regulated legislative issues about the research organization to include: a. organization, b. financing and c. evaluation, it seems that the university research production is constantly increasing.

The indicative statistics data of (2003) showing that 49,3\% of the research production in the country comes from the Higher Educational Institutions, when the average of the E.U. and OECD (Association for Quality Assurance in Higher Education, 2005; OECD, 2004) is 22,4\% and 17,3\% respectively (GSRT report, 2007). There is evidence, therefore, that research in Greek universities theoretically goes well and this is also shown practically by the research productivity (Ehrenberg, 1991), even if the state itself shows weakness in defining a legislative framework of organizing and utilizing research. 


\subsection{Research Institutes}

In Greece there are 17 University Research Institutes. It is mentioned that the biggest University in the country, Aristotle University of Thessaloniki, has no University Research Institute, neither has the University of Patra. In terms of geographical allocation 13 of them are in Athens (76,5\%), 1 in Thessaloniki (7,7\%), 2 in Crete (15,4\%), 1 in Ioannina $(7,7 \%)$.

It is observed that the research institutes are concentrated in big civic centers, whereas in the regional area there are fewer centers that seem to sub-function or to undertake research of smaller range or big research departments of central institutes.

At the same time, the research seems to be confined in the exact sciences and less in the theoretical domains. It is realized that the research institutes do not engage particularly with issues of social sciences, thus domains related to modern social issues are overlooked and the socio-political system does not receive any feedback regarding preoccupations over the individuals and groups social and political function.

\subsection{Laboratories}

There should be underlined, in the first place, that there is no clear legislative regulation about the laboratories work (Note 1). Their operation is at the disposal mainly of their internal functional regulation and there is not a more general framework about their organizational structure and object. Their mission is mainly teaching and research.

However, a look could be taken at the simple allocation of laboratories in some Higher Educational Institutions with a large number of social schools or schools with humanistic content. It is observed that in the University of Crete in a total of 70 laboratories only 15 are available to study social issues meaning that 15 function as social sciences laboratories. There are respectively: in Aristotle University of Thessaloniki 205 (6), NKUA/University of Athens 170 (43), University of Patra: 160 (35), University of Ioannina: 153 (33), Athens University of Economics: 28 (8), University of Macedonia: 0.

It is observed that the number of laboratories is limited resulting to difficulties upon the teachers' work that do not have the possibility to proceed into research of issues and contribute to study as well as theoretical and practical evolution.

This issue generates a negative condition in educating students that are not incorporated in research groups and are not engaged with the essence of scientific consideration and implementation. The theoretical orientation observed in Tertiary education penetrates all the educational system so that research is not deemed an area of education.

It is also realized that both in institutes and laboratories research is confined in exact sciences whereas it is exceptionally confined to social sciences. It should be noted that the new M.E.L.L.R legislative regulation about the HCI objectives investigation gives bigger possibilities for internal research financing in Higher Educational Institutions. This investigation gives them the opportunity to perform scientific, research, cultural and developmental programs through the HCI reserve funds credits for the benefit of their Institutions and following the recommendation of the Research Committee and the Higher Educational Institutions Assembly / Council decision.

\section{Critical analysis over the research production in the Greek universities}

Among the OECD countries, Greece, in 2005 indicatively, had 666 scientific publications per one million inhabitants, just 13 units over the OECD average but with the lowest publications impact factor among the E.U. countries. In 1995, just before the first E.U. support package results were presented, the country had 304 scientific publications per one million inhabitants, 247 units below the OECD average and impact factor of 0.49 ; ten hundredths below the last but one E.U. country, Portugal (Lehvo \& Nuutinen, 2006).

It can be assumed that the development of research production in Greece during the decade 1995-2005 is due to money influx through the European support packages. Since this assumption is valid then it can plausibly be accepted that the university research production, meaning that half of the domestic research production, did well as an outcome of the European financing. Therefore, it can be plausibly assumed that the quantitative and least qualitative increasing raise having been noted in the university research production is due to almost exclusively financing from abroad and possibly slightly or not at all to the domestic "self-financing". Should we combine the fact that in the same year (2005) there was the lowest investment in education in terms of the GNP percentage among the 15 European countries, it will be made easier understood that if something has changed in the university research production this is due to the financing from abroad. In other words, if the university research had some progress in Greece during the decade 1995-2005, this was perhaps due to the financing influx. The issue of European allocations seems to have assisted the research undertaking. In most cases, research activities, the objective of which is defined 
by the financier, are financed. It is the market that seems to give a pace in the research activity and this sense functions inhibitory regarding the free research activity. But can Greek universities rely only on this type of financing?

The main point, therefore, is whether the Higher Educational Institutions financing is sufficient so that all the TRP members working there can research and publish their research results. Is money enough for every TRP member to access the data bases $\mathrm{s} / \mathrm{he}$ is interested in, to access the scientific publications and organizations needed for his/her research, to be able to collect data from target populations without a hitch or, finally, to be able to publish his/her research results in congresses? A quick answer should not be given in the sense that the community support packages - for those having been financed - cover these needs. What happened with all those people that were not financed and what will happen when these programs come to an end?

There is one simple question: How can one or more TRP members conduct a research without the financing from abroad since, of course, money is required to carry out a research?

The first, and simplest, answer is: they pay the expenditures themselves. How many researches can a single TRP member finance by him/herself? Even if they were self-financed, should not they be publicized? Some of them should be sent out to journals and some others should be presented in congresses. Let alone the congress costs which, based on common prices, it is about 500 Euros for domestic congresses and 1000 Euros for abroad. How many congresses are there yearly? Researchers are therefore lead, many times, to anguished attempts of cutting the functional costs since nothing can be done about the publication costs. What happens in most cases? In most cases the absolute students" exploitation and usage that "within the framework of their studies" "help" the research conduction comes into limelight. A case like this may be institutionally right since students as scientists under training should learn to conduct researches. Do they, indeed, learn how to set up a research tool? Do they learn sample taking methods? Do they weigh up tools? Do they learn to process them? Do they learn to write down the results? Or do they merely function as multipliers? What happens when their work is determinant to the completion of a research? What participation percentage do they have in the research? This is going to be examined further on. It could be claimed that the monthly special research premium received by every TRP member covers his/her research needs. What is the amount of it and why is it granted? It is from 316 up to 426 (old prices before the cuttings) in relation to the grade "for the execution of post-doctoral research and the fastest and most effective promotion of research programs". This fact is ambiguous, difficult to be understood and needs to be further discussed.

\section{Functional obstacles and dysfunctions when conducting a research}

Let us have a look at problems related to rigidities of the Greek system. Whereas the research is theoretically supported, in practice, bureaucratic structures set terms that eventually make the research conduction difficult. Some problems occurring in a research which needs a students or teachers' sample are presented. A researcher must go to schools and ask from students or teachers to give some information to be used for research purposes. There are hereby presented some of the obstacles faced by the researcher:

1) Questionnaires distribution at schools without the M.N.E.R., which accepts or rejects after the Pedagogical Institute consultory response, is prohibited.

2) The Pedagogical Institute does not accept or reject merely the research tool, as it should be done, but requests for changes or modifications even for matters out of its jurisdiction (e.g. questions inconvenient or bothering about its members interests are rejected).

3) Temporal duration to grant a license, in some cases, lasted almost 1 year.

4) The reasoning for the documents requested is at least unrealistic.

5) University members research activity depends upon some people's will without any awareness of what they know or they do not.

The following example is very characteristic: an Aristotle University professor in whose cognitive object the definition "Pedagogical research methodology..." is included requested for a license from the Pedagogical Institute to conduct a research at schools. He submitted, as he ought to do, the relevant research tool (questionnaire) but received a negative answer. The Pedagogical Institute set for the issue of validity regarding sample taking, questions etc. The relevant discussion developed through a scientific magazine pages showed nothing more than the fact that university researches turn to be the prey before the judgment of a bureaucratic organization which, in any occasion, cannot guarantee the prevalence of its academic abilities in the university. Specific questions were rejected because 
the P.I. came to the conclusion that the students were not mature enough to answer them conducive to the research tool destruction.

Therefore, the only solution for the researcher lies in the sample illegal utilization carrying along collaborators, teachers, students and school directors. The research will either not be conducted or be conducted jeopardizing teachers and school directors. Therefore, it will not be conducted. Whatever has above been reported is equally a corresponding prohibition to doctors conducting researches in hospitals.

\section{About scientific ethics and morality}

Another look should now be taken at a last, but not of less significance, problem related to research in the Greek Higher Educational Institutions.

Scientific ethics refers to the implementation of basic ethical principles within a variety of issues related to scientific research. Such issues are the research designing and implementation, specifically when the research concerns humans or animals - directly or indirectly. Besides, research ethics also includes issues of piracy (plagiarism), data counterfeiting, violation of moral or professional codes, personality insult or animals maltreatment etc.

According to C. Robson "ethics [notably of science and research] is a total of principles and systems related to what is deemed right and / or wrong, behavioral models and codes" (Robson, 2007:648).

Ethics may be defined as "an issue of primary sensitivity against other people's privilege. The choices that can be made during the quest for truth are confined by ethics. Ethics contends that even though truth is good, the respect against human dignity is better even if, in extreme occasions, respect to human nature yields questions about the human nature".

Yet a problem remains concerning the fact that in case of agreement as well as privileges and obligations determination within the framework of ethics, it is possible that a final agreement is not reached according to hierarchy and the priorities definition regarding the above mentioned.

D. Baumrid (1964) deems that scientists, many times, show a weakness in perceiving their obligations against the research subjects because in the name of objectivity they keep a distance from the procedures to such an extent that they find it difficult to realize that they deal with humans. "Ethics" refers to individuals or collective "beliefs" about what is right or wrong. The "ethics code" refers, in particular, to professional behavior principles. According to D. Goodstein (2006) "a distinction between morality and ethics within the framework of social research, (lies) in that morality is usually deemed as exogenous whereas ethics refers to a profession standards that deal mostly with its members' conduct".

The terms "ethics" and "morality" are usually regarded as synonyms or identical. However, in their everyday use some differences are pin-pointed. The word morality is usually used for issues concerning the social conduct (see sexual behavior, in particular). The term ethics is used mainly about issues of institutional behavior (see scientific, in particular). M. Fowler and S. Fry (1988) go deep into this matter claiming that ethics is a systematic and stochastic research based on moral philosophy aiming at the formulation of a critical and stochastic morality. The classic theory of ethics argues that "duty" and reasoning formulate the basis of morality while the higher possession for someone is to distinguish duty in terms of sensibility, irrespective of any difficulty (Johnstone, 1987). M. Smith (1995:480) masterfully observes that "the comprehension of ethics is not merely a study of theoretical knowledge but it includes the comprehension of ethics implementation in real situations".

The basic moral principles are those having yielded a series of conduct codes, especially after 1945 . The most well-known include the Nurnberg Code (1947), the Geneva Declaration (1948-1994), the Human Rights Declaration (1990-1995), the Helsinki V Declaration (about the biomedical research on human subjects) (1964-1996) and the Belmont Report of 1979 (Hudson, 2001).

As an example, reference is made to the Belmont Report issued by the National Commission for the Protection of Human Subjects of Biomedical and Behavioral Research of the U.S.A. The Belmont Report made a synopsis of the basic ethical principles that were defined by the Committee during their meetings. In the Report the basic ethical principles and the guidelines that can help the resolution of ethical problems deriving during the conduction of a research on subjects are expressed.

In Greece, many times, the general University Faculties assemblies or the electoral bodies have engaged with accusations concerning bad scientific practices (research procedures, plagiarisms, series of names, multi-publications etc.). During the past time, these accusations have indeed penetrated the oppressive protective ring around universities and have appeared in the daily press. This incident can be explained either as a result of a pandemic 
violation of the academic practice ethical principles or as the fall of the privacy fortress, oaths of silence and protectionism that the academic community has generated for self-protection. On the other hand, nowadays, the control of scientific and writing work production procedures seems to be easier and in this sense this thickening of cases regarding violation of academic ethical rules looks like the natural outcome of the existing possibilities, despite the control tension - even if control usually appears to be an individual activity of some university entities since in Greece there is no institutional carrier entrusted with the academic work protection. It is peculiar, indeed, the fact that Greek Higher Educational Institutions literally give half of their academic function in a complex of good academic conduct rules of ceremonial character and to the benevolent intentions of their personnel in terms of protection and maintenance of the well-perceived academic honesty.

It should be claimed, of course, that piracy, for example, as an academic counter-ethical conduct is a penal offence penalized by the civic and penal law. There is no reason to disagree with this claim, but it can be easily supposed how difficult it is to confront a piracy on forensic level concerning a foreigner or domestic individual's publication who does not wish the pirate prosecution. Even in a case like this, the electoral bodies know well what can be done impertinent whether they eventually do it or not. In the last case, the pirate may simply remain without a penalty, be evolved and eventually prosecute other pirates throughout his career. On the other hand, a consideration lies whether the violation of research data is penalized or not. Is the violation against the anonymity of individual participants in the research conduction and who are medically or biologically examined or fill in some sort of questionnaire penalized? Should not such counter-ethical academic conduct cases be monitored and penalized? Should not cases in which university professors publish only under their own names or bargain the students' - postgraduate or undergraduate - works publications be monitored and penalized?

Suppose that a plausible answer for all these questions is found. Besides, it is very easy, when a piracy is ascertained, for the perpetrator to be controlled either through a common sworn administrative inquiry conducive to an internal disciplinary control or through a voting procedure. And this is because piracy is a legal offense and comes under the laws about copyright. Moreover, law unawareness is not an extenuation in any case. But should a research data violation be realized, what will happen? Should the anonymity violation of subjects participating in a research procedure is realized what will happen? Is there a legal framework that protects and monitors these procedures and their violators? If not, there is then a simple violators' appeal stating ignorance in these procedures that renders them immune. One should not beforehand claim that such a kind of violation will be taken under consideration because it is easy for someone to respond that such claims on the part of the electoral bodies will easily fall in a possible recourse because the violator has not violated any written rule, apart some good academic conduct practices. At this point, another plausible question is posed: Has any university professor and any university authority not considered to suggest regulations upon such issues without reaching the point of penalizing academic activity? For example, it is very simple to regulate all these issues through relevant reports - see academic ethics code - to the university institutions internal regulations. The M.N.E.R., of course, has decided to recommend to the Greek Higher Educational Institutions the composition of internal regulations in which stipulations relevant to ethics will be in force. In the P.D. 160/G.G. 220/2008 (Model Internal Regulation) it is mentioned that the Ethics Committee function (art. 4) "[...] aims at the ensuring, maintenance and implementation of ethics regulations [...]", as if they existed.

In the Greek Higher Educational Institutions some issues of academic ethics seem to circulate in the form of gossips among the academic community and remain, typically, powerless in exactly the same way gossips remain uncertified information. What is necessary has the same power as what is logically accepted and acquires this power as obvious reasoning - a reasoning which for some university entities may not be in force simply because some other reasoning dominates. At this point, the basic weakness of the academic ethics in Greece lies: on the depositing of its structural and functional guarantee on common sense which, in reality, is nothing else than a resultant of reasoning accepted and implemented by the academic community as an entirety. It is well known, of course, that the properties and characteristics of the entirety are not equalized with the properties and the characteristics of the parts. Individual reasoning and practices, therefore, are not always necessary to be consistent with the common or prevailing reasoning - especially when the last one cannot be set as a safety valve for good academic practice and protection of all the academic community members.

On the other hand, there are so many historical and sociological paradigms showing that informal rules and reiterated practices acquire, in many cases, the dynamics and power to dominate over formal rules and institutional social practices. It rests on the interaction and socialization procedures to ensure those prerequisites that will yield and protect ideological markings and practices guaranteeing what the social corpus every time deems common good or possession. In other words, the professional socialization procedures within the academic area protect good academic practice and establish a savoir faire on the academic community members. But should someone not show proper 
conduct what happens? Suppose that in the case of piracy one is prosecuted. But should one counterfeit research data for one's own benefit or for some assignor's benefit - namely the financier- what happens? It is made difficult to unveil. Suppose it is unveiled. Will one's name and work simply be disdained? Suppose this is what happens. Will one continue working by teaching what is necessary in science? Will someone not be imposed any administrative measures, at least? Can the university impose such measures in such a case?

Mature scientists and experienced university professors are very well aware of the fact that in research there are some things that should not be done. Some of them should not be done because this is what the well -understood academic practice implies and some others because they lie within the legal system stipulations. Besides, it is deemed that experience and scientific modesty are, in many cases, the safety valves that will prevent counter-ethical or illegal actions. But what happens with the young but tired or under formulation scientists agonizing to complete their studies and acquire a scientific reputation to enter the academic community? What happens with students and postgraduate students? Are they aware of the unwritten code of good practice in science?

In Greece there are not scientific ethics codes (Note 2) which are accessible to university institution personnel and students, contrary to the situation abroad where in most university institutions there are relevant codes and committees undertaking their maintenance and implementation. Greek students, therefore, learn from the first moment the procedures of completing their studies through the relevant syllabuses but they do not learn the proper way to do so. Even from the very first moment of their academic course they are not aware of the science savoir faire and were they not introduced to a university professor placing them within the framework of his/her subject, they would never be officially aware of it. It is likely, though, to be aware of scientific ethics through their apprenticeship by a university professor, the one that will define the qualitative framework. Should they be apprentices by some scientifically sensitive professor, they will learn the good practice. But, in any case, throughout the first years at university, an excuse such as: "I was not aware of that. How could I be aware of?" seems to stand up when no one takes care to inform them.

The outcome of scientific fraud is determinant to the total of individuals involved in the scientific production. A malicious scientific practice conduces to crucial erroneous decisions with economic and social consequences. The subsequent research attempts may also be disoriented. Apart from practical consequences within the scientific societies, of course, a scientific fraud damages the social image of science and those serving it as professionals. The trust towards institutions or companies where they work is also vacillated.

\section{Conclusion}

The university is an educational structure, a system that must and can cure science in terms of its research dimension. It is a public carrier that, as it should, transfers responsibilities to its personnel so that its aims are fulfilled. On this level, without, of course, the necessary state assistance, collective responsibility is transferred to individuals. This is legitimate. In order to have a functional responsibility some prerequisites are demanded. Are there these prerequisites? There exist only half of them. There exist institutional structures. As we have seen, the Greek state has not engaged with the research issue, so that the already existing university research laboratories and institutes are reinforced, by setting criteria, financing them and contributing to publication and utilization of findings. The fact that university research has been selectively enhanced by European programs is not a resolution since research should function systematically in all universities both in exact and theoretical sciences.

The Greek University seems to slowly make an attempt of disengagement from dysfunctional structures that make it marginalized and enfeebled. The necessity of constant re-frameworkings through continuous transformations that presuppose the de-construction of the educational policy itself for Universities could be pin-pointed; a policy that gradually through integration in the European Union does not seem to have the flexibility or the necessary resilience of its structures in order to manage the liquid economic situation and its relevant political and moral challenges.

The research and University education grid should be perceived as a relationships model within a conceptualization in which social progress and prosperity in Greece is tied to the attuned settlement of its educational structures. It is estimated that it should pass into a maturity stage through a universities and educational structures analysis so that an area of comprehending the morphological and structural dysfunctions should be formulated by redefining the truth of knowledge itself within a rational environment of settlement perhaps beyond the relativism of moral post-constructive or post -modern tensions. Research in university is related to three preoccupation levels: a) the theory of truth, b) the University community role and c) the conjunction of educational institutions with the social mainstream (Neumann, 2009). 


\section{References}

Althousser, L. (1990). State ideology and ideological mechanisms. Athens: Themelio.

Askenazy, P. (2004). Les Désordres du travail. Enquête sur le nouveau productivisme. Paris : Seuil.

Barnett, R. (1994). The idea of quality: voicing the educational in: G.D. Doherty, Developing Quality Systems in Higher Education. London: Routledge

Baumrid, D. (1964). Some thoughts on ethics on research. American Psychologist, 19(6), $421-423$. http://dx.doi.org/10.1037/h0040128

Berger, P. L. \& Luckmann. (2011). The Social Construction of Reality: A Treatise in the Sociology of Knowledge .London: Kindle.

Bologna Process. (2005). The European Higher Education Area- Achieving the Goals. Communiqué of the Conference of Ministers responsible for Higher Education. Bergen 19/20-5-2005.

Brannigan, A. (1981). The social basis of scientific discoveries. New York: Cambridge University Press.

Chalmers, A.F. (1982). What is this thing called science? Open University Press, Milton.

Colbeck, C. L. (ed). (2002). Evaluating Faculty Performance. San Francisco: Jossey-Bass

Colbeck, C.L. (1998). Merging in a seamless blend: How faculty integrate teaching and research, Journal of Higher Education 69(6). 647-71. http://dx.doi.org/10.2307/2649212

Communique of the European Ministers responsible for Higher Education. (2003). Realizing the European Higher Education Area, Berlin: Bologna Process.

Creamer, E. (1999). Knowledge production, publication productivity, and intimate academic partnerships, Journal of Higher Education 70(3),.261-77. http://dx.doi.org/10.2307/2649197

Clark, B. (1983). The higher education System: Academic Organization in Cross-national Perspective. London: University of California Press.

Doherty, G.D. (1994). Introduction: the concern for quality in G.D. Doherty. Developing Quality Systems in Higher Education. London: Routledge.

Ehrenberg, A. (1991). Le Culte de la performance. Paris :Hachette Litteratures.

GSRT report (2007). Reviews of Greece's Innovation Policy by the OECD. Athens: Ministry of Development.

Ellis, R. (1993). Quality Assurance for University Teaching. Buckingham: Open University Press.

European Association for Quality Assurance in Higher Education (2005). Standards and Guidelines for Quality Assurance in the European Higher Education Area.

Feller, I. (1990). Universities as Engines of R\&D-Based Economic Growth: They Think They Can, Research Policy 19(4), .335-48. http://dx.doi.org/10.1016/0048-7333(90)90017-Z

Feyerabend, P. (1975). Against Method: Outline of an Anarchist Theory of Knowledge. London: New Left Books.

Florida, R. (1999). The Role of the University: Leveraging Talent, Not Technology, Issues in Science and Technology, .67-73.

Fowler, M., \& Fry, S. (1988). Ethical Enquiry. in B. Sartor (Ed.). Paths to knowledge innovative research methods in nursing. New York: National League for Nursing.

Gibbons, M. (1998). Higher Education Relevance in the $21^{\text {st }}$ Century. Paper supported by the World Bank as part of its contribution to Unesco World Conference on Higher Education. Paris October 5-9 1998.

Gibbons, M. (2006). The new production of knowledge. The dynamics of science and research in contemporary societies. London: Sage.

Goodstein D. Scientific Misconduct. $\quad$ Retrieved $20 \quad$ January, $2012 \quad$ from http://www.med.umich.edu/pibs/pibs501.503/2006_files/GoodsteinDishonestyinScience.doc

Gull, K. (2010). The chasm between teaching and research. New Scientist, Retrieved 22 January, 2012 from http://www.newscientist.com/blogs/thesword/2010/03/academy-the-chasm-between-teac.html

Hill, K., Hoffman, D. \& Rex, T. (2005). The Value of Higher Education: Individual and Societal Benefits, Center for Competitiveness and Prosperity Research, Arizona State University. 
Hindmoor, A. (2004). The Construction of Political Space: New Labour at the Centre. Oxford: Oxford University Press. http://dx.doi.org/10.1093/0199273146.001.0001

Hobsbawm, E. (2011). How to change the world. Marx and Marxism 1840-2011. London: Little, Brown.

Hudson, S. (2001). Ethics for Alternative Paradigms: An Exploration of Options. Retrieved 20 December, 2011 from $\mathrm{http} / / / \mathrm{www}$.graduateresearch.com/hudson.htm

Jessop, B. (2002). The future of the Capitalist State. Cambridge: Polity Press.

Johnstone, M.J. (1987). Professional ethics in nursing: a philosophical analysis. The Australian Journal of Advanced Nursing, 4,(3), 12-21.

Koubi, G. (2000). L' egalite des chances. Analyses, evolutions, perpectives. Paris: La Decouverte.

Kuhn, T. (1962). The Structure of Scientific Revolutions. Chicago: University of Chicago Press.

Lehvo A. \& Nuutinen, A. (2006). Finnish Science in International Comparison: A Bibliometric Analysis. Helsinki: Academy of Finland.

Martin, B. (1981). The scientific straightjacket. The Ecologist, 11,. 33-43.

Merton, R. K. (1968). Science and Democratic Social Structure. in R.K. Merton Social Theory and Social Structure. New York: Free Press, 604-605.

Mulkay, M. J. (1976). Norms and ideology in science. Social Science Information, 15(4/5): 637-656. http://dx.doi.org/10.1177/053901847601500406

Nachman, B.-Y. (1986). Deviance in Science: Towards the Criminology of Science. The British Journal of Criminology, 26 (1), 1-27.

Neumann, A. (2009). Professing to Learn: Creating Tenured Lives and Careers in the American Research University, Baltimore: The John Hopkins University Press.

OECD. (2004). Internationalisation and Trade in Higher Education, Opportunities and Challenges. Paris: OECD.

Osmond, D. (1983). Malice's wonderland. Research funding and peer review. Journal of Neurobiology, 14, 95-112. http://dx.doi.org/10.1002/neu.480140202

Radford, J. (1997). The changing Purposes of Higher Education, in J. Radford, K. Raaheim, P. Vries \&R. Williams. Quantity and Quality in Higher Education. London: Jessica Kingsley Publishers.

Ravetz, J. R. (1971). Scientific knowledge and its social problems. New York: Oxford University Press.

Robson, C. (2007). Real World Research (in Greek). Athens: Gutenberg,.

Smith, D.O. (2011), Managing the Research University, Oxford: Oxford University Press. http://dx.doi.org/10.1093/acprof:oso/9780199793259.001.0001

Smith, M.W. (1995). Ethics in focus groups: A few concerns. Qualitative Health Research, 5 (4). 478-486. http://dx.doi.org/10.1177/104973239500500408

Vest, C.M. (2007). The American Research University from World War II To World Wide Web; Governments, the Private Sector and the Emerging Meta-University, Berkeley: University of California Press.

\section{Notes}

Note 1. It is worth noting that on 15/4/2010 the Ministry of National Education and Religion had not any index of the laboratories operating in the Greek Higher Educational Institutions. The information cited was gathered by the institutions websites. Mistakes are likely to appear.

Note 2. An impromptu investigation through the Internet yielded a general research ethics code of the Aristotle University of Thessaloniki Research Committee (see http://web.auth.gr/dent/web/el/info/parartima_bl.doc). The same investigation also unveiled that there are some scientific-professional ethics codes such as those of the Greek Sociologists Association (see http://www.sociology.gr/deontologia.sociology.htm) and the Greek Psychologists Association (http://www.seps.gr/docs/code_seps.DOC) etc. There is, of course, the National Bioethics Committee (www.bioethics.gr). Only some of the international professional associations having developed ethics codes are the following: American Psychological Association (A.P.A.), British Sociological Association (B.S.A.), Social Research Association (S.R.A.). 
Table 1. Laboratories and TRP members in Greek Universities

\begin{tabular}{|l|l|l|l|}
\hline $\begin{array}{l}\text { Higher Educational } \\
\text { Institutions }\end{array}$ & $\begin{array}{l}\text { Number of } \\
\text { laboratories }\end{array}$ & $\begin{array}{l}\text { Number } \\
\text { of TRP }\end{array}$ & $\begin{array}{l}\text { RTP members } \\
\text { proportion per } \\
\text { laboratory }\end{array}$ \\
\hline University of Crete & 70 & 647 & 0,11 \\
\hline $\begin{array}{l}\text { Aristotle University of } \\
\text { Thessaloniki }\end{array}$ & 205 & 2877 & 0,07 \\
\hline NKUA & 170 & 2409 & 0,07 \\
\hline University of Patra & 160 & 985 & 0,16 \\
\hline University of Ioannina & 153 & 688 & 0,22 \\
\hline $\begin{array}{l}\text { Athens University of } \\
\text { Economics }\end{array}$ & 28 & 275 & 0,10 \\
\hline University of Macedonia & 0 & 307 & 0 \\
\hline Total & 786 & 8188 & 0,095 \\
\hline
\end{tabular}

